\title{
INTRAVENOUS MAGNESIUM SULFATE IN THE TREATMENT OF NEPHRITIC CONVULSIONS IN ADULTS 1,2
}

\author{
By ALEXANDER W. WINKLER, PAUL K. SMITH, AND HEBBEL E. HOFF \\ (From the Department of Internal Medicine and the Laboratories of Pharmacology and \\ Physiology, Yale University School of Medicine, New Haven)
}

(Received for publication November 1, 1941)

Since 1926 the intravenous injection of magnesium sulfate has been employed in this clinic for the treatment of the twitchings and convulsions of advanced chronic nephritis in adults. This report is based on over forty cases so treated. Cases of eclampsia, acute nephritis of childhood, and various other vascular disorders also treated with intravenous magnesium sulfate have been included. For comparative purposes the physiological effects of intravenous magnesium were observed in subjects without cardiovascular disease.

\section{REVIEW OF LITERATURE}

On the basis of animal experiments Meltzer (1) recommended the use of magnesium intravenously in the treatment of tetanus, and there have been several reports of cases treated in this way $(2,3)$. In 1916 Peck and Meltzer described three cases in which magnesium sulfate was employed intravenously as a general surgical anesthetic (4). However, amounts sufficient to induce anesthesia were found to produce marked respiratory depression, so intravenous magnesium proved impractical as a general anesthetic. Attempts have been made to use it in combination with other anesthetics, but such suggestions have met with little favor (5).

In 1923 Blackfan (6), on the basis of Meltzer's work, introduced intravenous magnesium sulfate therapy in the treatment of the convulsions of acute nephritis in children. He was convinced of the efficacy of the treatment on purely clinical grounds, but was uncertain as to the exact mode of action. Originally, Blackfan was impressed with the importance of cerebral edema in the etiology of convulsions in his patients and combined intravenous magnesium sulfate therapy with dehydration produced by magnesium sulfate catharsis. Since magnesium sulfate intravenously injected acts through the specific pharmacological action of the magnesium ion, while its effects

1 Aided by grants from the Ella Sachs Plotz Fund, the Committee on Therapeutics of the American Medical Association, and the Fluid Research Fund of the Yale University School of Medicine.

2 A preliminary report was presented to the American Society for Clinical Investigation in May 1940; J. Clin. Invest. (Proc.), 1940, 19, 783. are simply those of any saline cathartic when it is given orally, it is clear that two quite different modes of treatment were used in conjunction by Blackfan. In his earlier reports he is not clear as to the relative importance of the specific magnesium ion effects and of the nonspecific dehydration effects. If cerebral edema were as important a factor in these cases as he originally believed, then dehydration should be most effective, and specific nervous system depression by magnesium should be harmful rather than otherwise; this, however, did not seem to be the case. In his last report in 1931 (7) he is inclined to stress the importance of dehydration but recognizes that intravenous magnesium sulfate may be quite effective without any dehydrating measures. Whatever the mode of action, Blackfan's work demonstrates that in acute nephritis of children the intravenous injection of magnesium sulfate in isotonic or hypotonic solution lowers blood pressure, stops convulsions, and in many instances is followed by immediate clinical improvement. It is remarkable that these effects are produced by amounts of magnesium sulfate far smaller than those required in Meltzer's experiments to produce anesthesia or to check tetanic spasms. Rubin and Rapoport (8) have also reported favorably on the use of intravenous magnesium sulfate in children but have emphasized the occasional dangers.

In 1925 and 1926 Lazard (9), Alton and Lincoln (10), and Lazard, Irwin and Vruwink (11) reported favorably upon the use of intravenous magnesium sulfate in controlling the convulsions of eclampsia, and it has since been used quite extensively for this purpose $(12,13)$. Its use, however, has been empirical, and its mode of action but little studied.

\section{MATERIAL AND METHODS}

Adult patients ordinarily received intravenously $500 \mathrm{cc}$. of a 2 per cent solution of the hydrated salt, $\mathrm{MgSO}_{4} \times$ $7 \mathrm{H}_{2} \mathrm{O}$, during a thirty- to sixty-minute period. Sometimes smaller or larger amounts were given. The rate of injection was occasionally altered during the course of the infusion. The injection of $500 \mathrm{cc}$. was repeated after a few hours if convulsions recurred or if twitchings suggested that another convulsion might be impending. In a few instances a third injection was given. Over twenty of these cases have been observed by one of us (A. W. W.) during the course of the infusions. In the remainder it has been necessary to rely upon observations recorded 
in the chart; only those cases are included in which notes were made by observers of known competence. ${ }^{3}$

In most patients blood pressure was followed during and after the infusion. In certain cases serial electrocardiograms from lead two were taken. Concentrations of magnesium in serum, urine and feces were determined in a number of instances, using chemical methods previously described (14). Cerebrospinal fluid pressure was followed during the infusion in one case.

\section{RESULTS}

\section{(A) Cardiovascular effects}

Flushing, perspiration and a subjective sensation of extreme warmth were reported by all the conscious patients. This was usually first noted within less than half a minute after the commencement of the injection, and continued to a greater or less degree throughout the infusion. The face, neck and hands were particularly affected, and a rise in skin temperature was easily demonstrated. These evidences of cutaneous vasodilatation were as marked in subjects with acute and chronic vascular disease as in normal subjects. The intensity of the effect depended in part on the rate of injection.

Blood pressure was essentially unchanged during the infusion in four control subjects without cardiovascular disease, while in three others it dropped sharply (Figure 1). The drop, when it occurred, was usually quite sudden. Blood pressure varied but little during the earlier stages of the infusion; then quite suddenly both systolic and diastolic pressures broke sharply, and within one or two minutes might drop so low that they were difficult to measure (Figure 2). The fall in blood pressure sometimes continued for one or two minutes after the infusion had stopped. Within the next five or ten minutes the pressure then returned promptly to the normal range. This sharp collapse in blood pressure was regularly accom-

${ }^{3}$ For help in this connection we are indebted to the entire past and present staff of the Metabolism Division of the Department of Medicine. Particular use has been made of the meticulous observations of certain cases by the late Dr. Maurice Wakeman, who originally introduced the use of intravenous magnesium sulfate in this clinic in 1926. Dr. John P. Peters has had the responsibility for directing the treatment since its introduction and has made available the records of cases not studied by us personally. Acknowledgment is made to Dr. Arthur $\mathbf{H}$. Morse and to Dr. Grover F. Powers for permission to include the obstetrical and the pediatric cases.

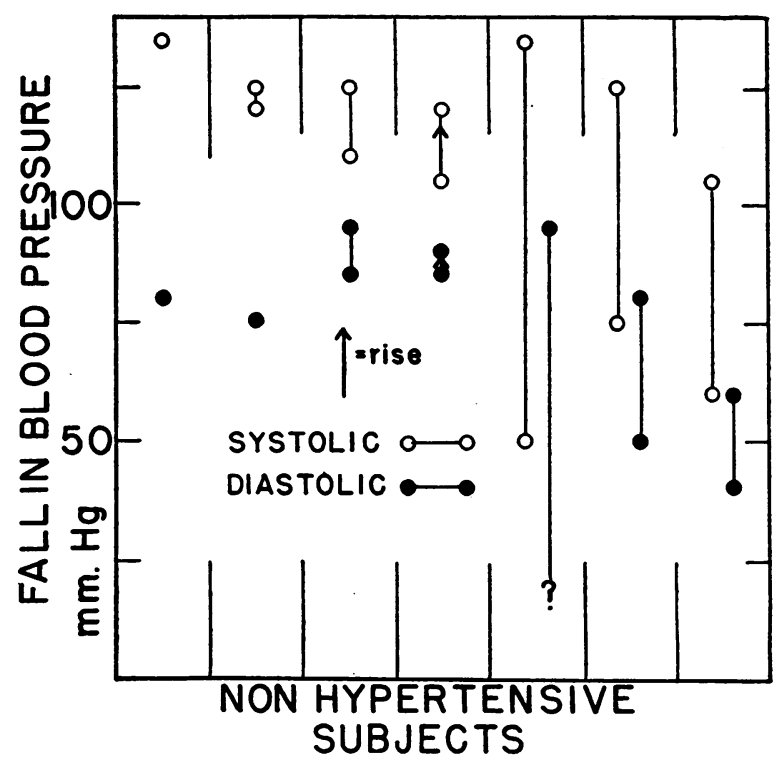

Fig. 1. Effect of Intravenous Magnesium Sulfate on the Blood Pressure of Seven Subjects Without Hypertension or Vascular Disease

The upper circle in each case represents the initial blood pressure; the lower, the minimum pressure reached during or after the injection. In the first four subjects there was no significant fall in blood pressure, while in the last three there was sudden collapse. One unresponsive patient received $250 \mathrm{cc}$., the other three $500 \mathrm{cc}$. each. The patients exhibiting decline of blood pressure received 220 , 370 and 375 cc., respectively, of 2 per cent magnesium sulfate.

panied by nausea, thirst, extreme restlessness, mental confusion and a subjective sense of imminent doom. These alarming symptoms disappeared at once when the pressure rose again after stopping the infusion. So disturbing were these manifestations that at the height of the reaction adrenalin was administered to one subject and intravenous calcium chloride to another. Since recovery was as rapid in the third untreated case as in these two, these procedures cannot be held solely responsible for the rapid return of the blood pressure to normal. The pulse rate was always slow during the period of hypotension. The four subjects exhibiting no significant fall in blood pressure complained of no such violent subjective disturbances but only of a feeling of warmth.

The response of the blood pressure in patients with cardiovascular and renal disease to the intravenous injection of magnesium sulfate in certain respects resembled, and in others differed from, 


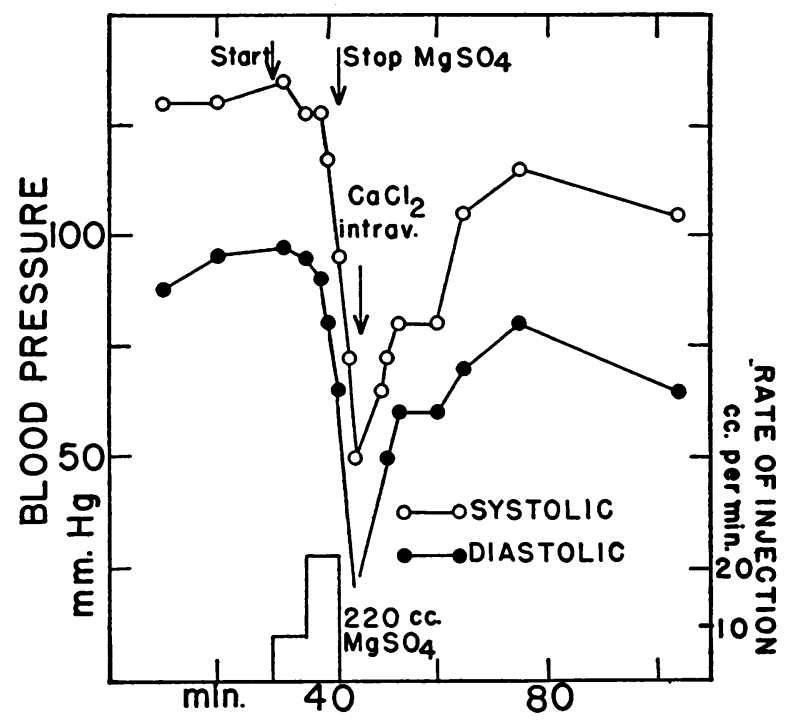

Fig. 2. Sudden Collapse of Blood Pressure in a Normal Subject While Receiving Magnesium SulFATE INTRAVENOUSLY

Just after the termination of the injection the patient was unconscious and the diastolic pressure was unobtainable. $\mathrm{CaCl}_{2}$ was given intravenously at this time. Recovery was complete within a few minutes. that of subjects without vascular disease. As with normal subjects, the blood pressure was but little affected in one group of cases (Figure 4), while it fell markedly in another group (Figure 3). The different types of chronic renal and cardiovascular disease were evenly distributed between the two groups which were indistinguishable on the basis of age and sex distribution or on the basis of amount or rate of injection of magnesium. In occasional cases the blood pressure reacted at one time and failed to react at another during the course of the same illness. In contrast to this irresponsive behavior of many of these chronic patients, the blood pressure fell promptly in all but one of the subjects with eclampsia and acute nephritis (Figure 5).

In one important respect the reaction of hypertensive subjects differed from that of those without cardiovascular disease. The sharp collapse of the blood pressure in normal subjects receiving intravenous magnesium was rarely observed in those with hypertension. On the contrary, the blood pressure usually fell rather slowly and gradu-

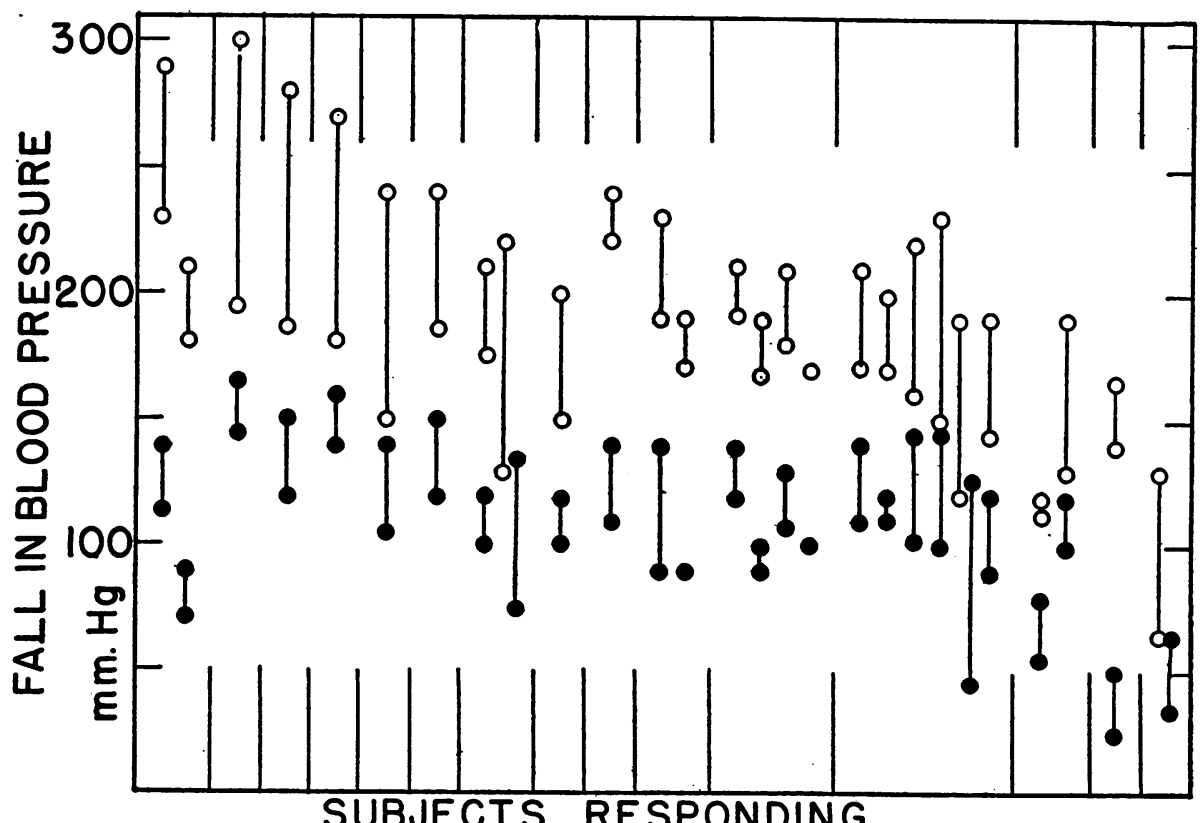

Fig. 3. Change in Blood Pressure following Intravenous Magnesium Sulpate in the Fifteen Subjects With Chronic Renal and Vascular Disease Whose Pressure Did Decline

The symbols are the same as those used in Figure 1. Multiple injections in the same patients are indicated by the bracketing lines at the top and bottom. The usual dose was 500 cc. in each injection. 


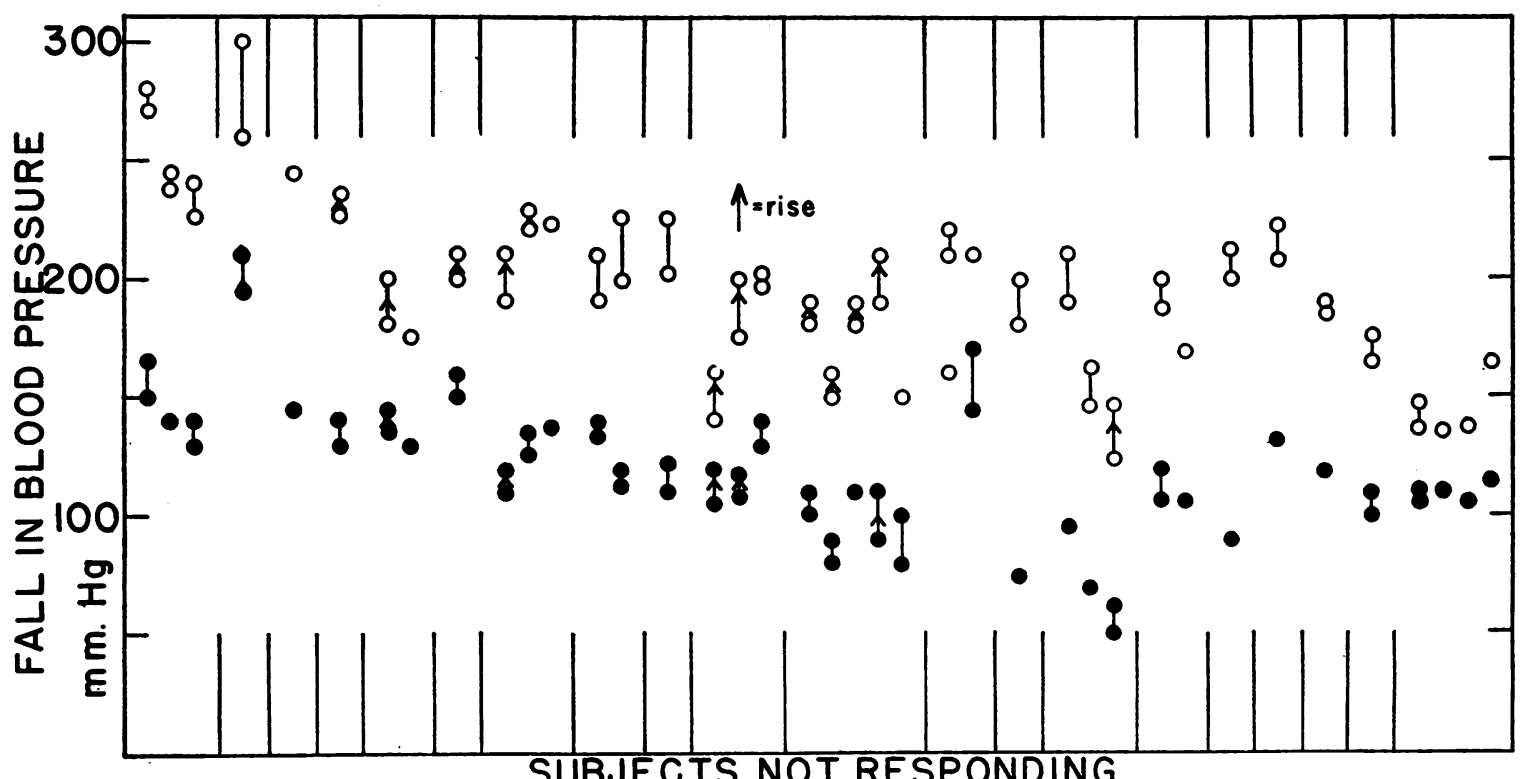

Fig. 4. Change in Blood Pressure Following Intravenous Magnesium Sulfate in the Twenty Subjects With Chronic Renal and Vascular Disease Whose Pressure Did Not Decline Significantly

The symbols are identical with those used in Figures 1 and 3. The usual dose was $500 \mathrm{cc}$.

ally (Figure 6) without any distressing subjective symptoms. It was hardly ever necessary to discontinue the infusion because of symptoms associated with fall in blood pressure, and the shocklike levels reached in normal subjects were seldom seen. The degree to which blood pressure fell was

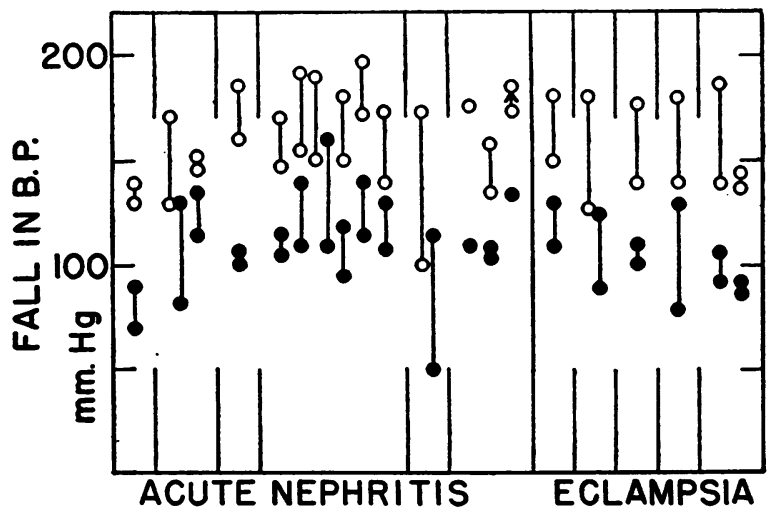

Fig. 5. Change of Blood Pressure following Intravenous Magnesium Sulfate in Six Subjects With Acute Nephritis and in Five Subjects With ECLAMPSIA

The symbols are identical with those used in previous figures. The subjects with acute nephritis were children, the dose varying between $100 \mathrm{cc}$. and $300 \mathrm{cc}$. The eclampsia patients usually received $500 \mathrm{cc}$. not closely correlated with the amount of magnesium which had been given but rather with the rate of administration. It is not unlikely that some of the "unresponsive" subjects, with or without cardiovascular disease, might have developed hypotension if the rate of infusion had been greatly accelerated. The fall in blood pressure, when it occurred, was apt to be somewhat more persistent in the hypertensive than in the normal subjects, frequently lasting half an hour to an hour and occasionally lasting several hours. The return to the previous level took place in spite of the continued presence of an increased concentration of magnesium in the serum (Table II).

No correlation could be found between cessation of convulsions and the presence or absence of blood pressure changes. Electrocardiograms were taken during the entire course of magnesium injection in six instances. Minor changes only were observed, consisting chiefly of slowing and slight prolongation of the PR interval. No intraventricular block and no arrhythmia were detected. The only case in which the prolongation of the PR interval was at all evident was also the one in which the serum magnesium reached the highest concentration found in this series. 


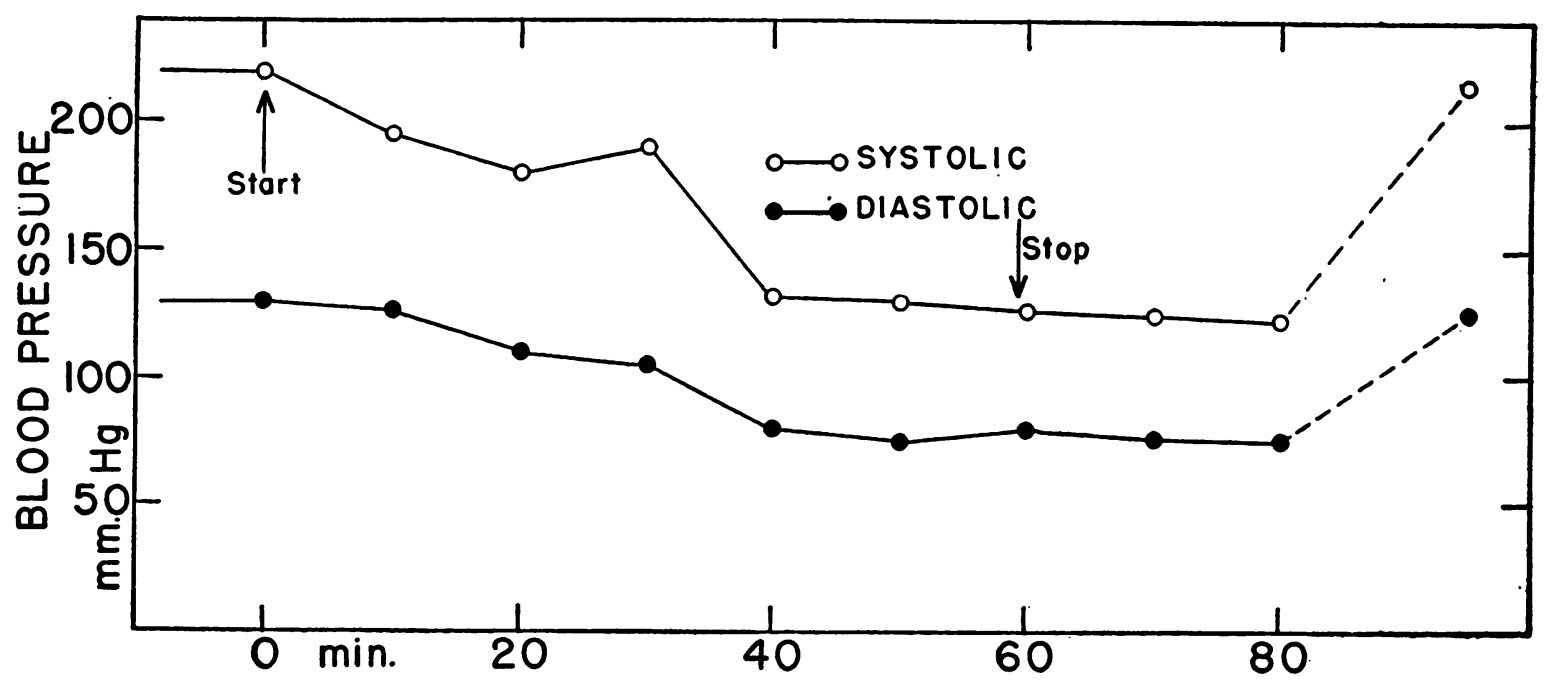

Fig. 6. Gradual Decline of Blood Pressure During the Intravenous Injection of 500 cc. of Magnesium Sulfate in a Patient With Chronic Glomerulonephritis and Severe Hypertensive Cardiovascular Disease

\section{(B) Effects on convulsions and twitchings}

It is difficult to evaluate the effect of any therapeutic measure on the convulsions in "uremic" patients for several reasons. First, only a portion of the patients with pre-terminal nitrogen retention and manifestations of "uremia" develop convulsions. Although twitching of the musclessometimes fibrillary, sometimes involving whole muscles and groups of muscles-is often a prelude to the development of actual convulsions, the appearance of convulsions is by no means invariable. Secondly, therapy instituted after the development of convulsions cannot readily be evaluated since convulsions tend to disappear spontaneously. Finally, the great majority of the patients studied here were near death when therapy was instituted, since convulsions and twitching in chronic nephritis with nitrogen retention seldom occur until shortly before death. Failure of convulsions to recur after a single injection in many cases was therefore inevitable. Nevertheless it was possible to make an analysis of the relation of the convulsions to therapy. This is presented in Table I.

Some two-thirds of the cases of chronic nephritis with convulsions had no more convulsions after a single injection of magnesium sulfate, while the remaining third required two injections. No patient who received full amounts in each injection required more than two injections. The precise interpretation of this apparently effective control of convulsions is uncertain, since it is impossible to say how many patients in an untreated group

TABLE I

Effectiveness of intravenous magnesium sulfate in relieving conoulsions and muscular twitching

Cases receiving magnesium for other causes are not included.

Group A: Chronic nephritis with convulsions (25 cases) Complete cessation of convulsions after one injection *

Complete cessation of convulsions after two injections

Complete cessation of convulsions after three injections $\dagger$

In only one of these 25 cases had the patient been given magnesium therapy for twitching prior to the development of convulsions.

Group B: Chronic nephritis without convulsions but with twitching (9 cases)

"Believed helpful"

"Believed useless"

Uncertain

In none of these nine cases did actual convulsions develop.

Group C: Acute nephritis with convulsions and subsequent recovery in children ( 2 cases)

Convulsions ceased after one injection

Single recurrence after one injection

Group D: Eclampsia and convulsions (8 cases)

Convulsions ceased completely after one injection $\ddagger$

Convulsions ceased completely after two injections

* In three instances convulsions recurred after a free interval of a week or more.

$\dagger$ Convulsions continued during the third injection. The first two injections were half the usual size.

$\ddagger$ Of these one died during the infusion and one died twelve hours after the infusion. 
of cases would have had more than two sets of convulsions. It is our general clinical impression that, while convulsions are often single in uremia, cases are not infrequently met with in which repeated sets of convulsions occur. If this be so, there are grounds for believing that magnesium therapy is effective, since in every instance in our treated series convulsions were readily controlled.

More definite is the fact that, considering groups $\mathrm{A}$ and $\mathrm{B}$ together, in only one instance out of the ten in which preliminary twitchings had been treated with magnesium did convulsions develop. Since twitchings are ordinarily so frequently followed by convulsions, it seems almost certain that this represents a genuine prophylactic action of magnesium. The effects of magnesium in stopping the twitching itself are very slight. In no instance was magnesium followed immediately by disappearance of the twitching.

Magnesium is apparently effective in controlling the convulsions in acute nephritis and in eclampsia (Table I, groups C and D). It is difficult to interpret these figures, however, since convulsions are somewhat less apt to be persistently recurrent in cases of this type, and the total number of cases studied is small.

\section{(C) General clinical improvement}

Notes stating that there was a "general clinical improvement" are frequently found in connection with the eclampsia and acute nephritis cases and are notably absent in the cases with chronic nephritis. This is such a vague expression that extended discussion is out of place in an attempt at objective evaluation of the results of therapy. Diuresis was but little stimulated; vomiting and mental status were not often affected. A deep natural sleep sometimes occurred not long after the infusion.

\section{(D) Effects on cerebrospinal fluid pressure}

It is well known that, whatever may be the case with the acute nephritis of children, the brains of adult uremic patients do not regularly show edema at autopsy (15). Lumbar puncture frequently reveals a slightly increased pressure during life, but rarely a markedly increased pressure (16). Of the seven instances in this series in which lumbar punctures were done, a significantly in- creased pressure was found in only one, a patient who proved at autopsy to have a meningioma. In view, however, of Blackfan's suggestion that intravenous magnesium sulfate might in some manner achieve its effects by lowering cerebrospinal fluid pressure, a lumbar puncture needle attached to a manometer was inserted in the spinal canal just before an infusion of magnesium sulfate. The patient was a stuporous young woman in the last stages of glomerulonephritis who had been having convulsions shortly before the infusion. Before the infusion the cerebrospinal fluid pressure was $260 \mathrm{~mm}$. of water, during the half hour infusion it was $230 \mathrm{~mm}$., and for some time thereafter it remained at this same level. Evidently magnesium sulfate had no significant effect on the cerebrospinal fluid pressure in this case.

\section{(E) Untoward reactions}

Some 100 or so injections were given to fiftythree patients, most of whom were in a pre-mortal state with advanced renal and cardiac disease. Nevertheless death only occurred once during an infusion, and this was just after the infusion had begun. This patient was desperately ill with an acute eclamptic syndrome, and it is probable that she would have died within an hour or so even if no magnesium sulfate had been given. With this single exception no serious ill effects which might have been ascribed to the magnesium were noted. ${ }^{4}$ The sudden fall of blood pressure occasionally appeared alarming but was never followed by any persistent shock-like state. Even after hypoten-

4 Through the courtesy of Dr. Charles Aring we have been informed of a fatality immediately following the rapid intravenous injection of $30 \mathrm{cc}$. of 25 per cent magnesium sulfate. This patient received in less than a minute as much magnesium as that contained in 375 cc. of our 2 per cent solution. Such a rapid injection produces a sudden great elevation of magnesium in the serum followed by a rapid fall. The maximal concentration attained in serum under these circumstances depends as much upon rate of injection as upon the amount injected, so that it is difficult to control it with any precision. In view of the narrow margin between effective and dangerous concentrations, this is a serious objection. The occurrence of this fatality emphasizes the dangers inherent in the rapid intravenous injection of concentrated solutions of magnesium sulfate. In our therapeutic practice we use no greater concentration than 2 per cent, and allow at least half an hour for the injections of $500 \mathrm{cc}$. 
sion had been established by the infusion of magnesium sulfate, a convulsion invariably raised blood pressure, indicating that vasoconstrictor mechanisms were still effective and that blood pressure was not fixed at the low level. Amounts sufficient to cause failure of spontaneous respiration were never used. Vomiting during the infusion occurred twice.

(F) Concentrations in the blood, and excretion

In Table II are presented analyses of serum for magnesium before and after infusion in nine subjects. In four of them urinary excretion, and in one excretion in the stools, was studied as well. The serum concentration immediately following the infusion usually ranged from 4 to 10 m.eq. per liter, although in two instances a concentration of 13.3 m.eq. per liter was found. These high values were associated with slight shallowness and slowing of respiration but no respiratory failure. Knee jerks, however, were absent. Patient Number five was comatose before and during the infusion; but patient Number eight was awake and cooperative. Toward the

TABLE II

Magnesium in serum, urine and stools

\begin{tabular}{|c|c|c|c|c|c|c|c|c|c|c|}
\hline \multirow{3}{*}{$\underset{\text { ber }}{\text { Num- }}$} & \multirow{3}{*}{ Diagnosis } & \multirow{3}{*}{ Date } & \multirow{3}{*}{$\begin{array}{c}\text { Body } \\
\text { weight }\end{array}$} & \multirow{3}{*}{$\begin{array}{l}\text { Blood } \\
\text { NPN }\end{array}$} & \multicolumn{6}{|c|}{ Magnesium } \\
\hline & & & & & \multirow[b]{2}{*}{ Injected } & \multicolumn{3}{|c|}{ Serum } & \multirow{2}{*}{$\begin{array}{c}\text { Urine } \\
24 \text { hours } \\
\text { after } \\
\text { infusion }\end{array}$} & \multirow{2}{*}{$\begin{array}{l}\text { Volume } \\
\text { of } \\
\text { distri- } \\
\text { bution }\end{array}$} \\
\hline & & & & & & Initial & $\begin{array}{c}\text { After } \\
\text { infu- } \\
\text { sion }\end{array}$ & $\underset{\substack{\text { Nert } \\
\text { morng- } \\
\text { Ning }}}{\mid}$ & & \\
\hline & & & kgm. & $\underset{\substack{\text { per } \\
\text { cert }}}{\operatorname{mgm.}}$ & m.eq. & \multicolumn{3}{|c|}{ m.eq. per liter } & m.eq. & $\begin{array}{c}c c . \text { per } \\
\text { kgm. }\end{array}$ \\
\hline (1) & $\begin{array}{l}\text { Chronic nephritis } \\
\text { with edema }\end{array}$ & December 12 & 60 & 250 & 81.3 & 4.9 & 8.4* & 7.5 & & 36 \\
\hline (2) & Eclampsia & February 2 & 50 & 40 & 122.1 & 2.7 & $5.8^{*}$ & & & \\
\hline (3) & $\begin{array}{l}\text { Chronic nephritis } \\
\text { with edema }\end{array}$ & $\begin{array}{c}\text { November } 15 \\
\text { November } 17 \\
\text { November } 18 \text { to November } 21 \\
\text { November } 27 \\
\text { November } 27 \text { to December } 5\end{array}$ & 50 & $\begin{array}{l}185 \\
200\end{array}$ & $\begin{array}{l}37.7 \\
73.2\end{array}$ & $\begin{array}{l}2.4 \\
2.0 \\
2.0\end{array}$ & $\begin{array}{l}4.3 \\
5.4\end{array}$ & $\begin{array}{l}2.6 \\
4.5\end{array}$ & $\begin{array}{l}1.0 \\
4.4 \dagger \\
1.4 \\
3.0 \dagger\end{array}$ & $\begin{array}{l}37 \\
40\end{array}$ \\
\hline (4) & $\begin{array}{l}\text { Chronic pyelo- } \\
\text { nęphritis }\end{array}$ & $\begin{array}{l}\text { February } 10 \\
\text { February } 19 \\
\text { February } 23\end{array}$ & 60 & $\begin{array}{l}113 \\
129 \\
173\end{array}$ & $\begin{array}{l}81.3 \\
81.3 \\
81.3\end{array}$ & $\begin{array}{l}1.6 \\
2.6 \\
4.8\end{array}$ & $\begin{array}{l}6.6 \\
7.1 \\
8.9\end{array}$ & $\begin{array}{l}4.3 \\
5.9 \\
8.0\end{array}$ & & $\begin{array}{l}25 \\
28 \\
31\end{array}$ \\
\hline (5) & $\begin{array}{l}\text { Chronic nephritis } \\
\text { with edema }\end{array}$ & $\begin{array}{l}\text { May } 16 \\
\text { June } 21\end{array}$ & 52 & $\begin{array}{r}84 \\
150\end{array}$ & $\begin{array}{r}122.0 \\
97.6\end{array}$ & $\begin{array}{l}1.7 \\
6.7 \ddagger\end{array}$ & $\begin{array}{r}7.7 \\
13.3\end{array}$ & $\begin{array}{r}4.4 \\
12.2\end{array}$ & 9.2 & $\begin{array}{l}36 \\
26\end{array}$ \\
\hline (6) & Chronic nephritis & October 21 & 55 & 145 & 81.3 & 1.8 & 6.4 & & & 30 \\
\hline (7) & $\begin{array}{l}\text { Chronic nephritis } \\
\text { with slight edema }\end{array}$ & $\begin{array}{c}\text { December } 16 \\
\text { December } 16 \text { to December } 18\end{array}$ & 60 & 200 & 81.3 & 4.3 & 10.8 & 7.08 & 7.5 & 19 \\
\hline (8) & $\begin{array}{l}\text { Acute necrotizing } \\
\text { hypertensive dis- } \\
\text { ease }\end{array}$ & $\begin{array}{l}\text { December } 29 \\
\text { December } 30 \\
\text { December } 31 \\
\text { January } 5 \\
\text { January } 6 \\
\text { January } 8 \\
\text { January } 10\end{array}$ & 50 & $\begin{array}{l}50 \\
24\end{array}$ & $\begin{array}{l}81.3 \\
81.3 \\
81.3 \\
81.3 \\
61.0 \\
81.3 \\
81.3\end{array}$ & $\begin{array}{l}2.3 \\
? \\
2.8 \\
2.5 \\
2.4 \\
1.9 \\
2.4\end{array}$ & $\begin{array}{r}9.8 \\
11.0 \\
13.3 \\
8.5 \\
8.4 \\
10.5 \\
7.7\end{array}$ & $\begin{array}{l}4.9 \\
2.8 \\
3.0 \\
2.4 \\
1.98 \\
2.48\end{array}$ & 83.0 & \\
\hline (9) & $\begin{array}{c}\text { Chronic nephritis } \\
\text { without edema }\end{array}$ & March 4 & 55 & 50 & 81.3 & 1.5 & 4.4 & 2.5 & & \\
\hline (10) & $\begin{array}{c}\text { Chronic nephritis } \\
\text { without edema }\end{array}$ & $\begin{array}{l}\text { May } 29 \\
\text { May } 30 \\
\text { May } 31\end{array}$ & 50 & 45 & $\begin{array}{l}81.3 \\
81.3 \\
81.3\end{array}$ & 2.3 & $\begin{array}{l}6.7 \\
8.2 \\
8.5\end{array}$ & & & \\
\hline
\end{tabular}

* Six hours after infusion.

† Stool magnesium 2.6 and 4.5 m.eq. per 24 hours during these two periods, respectively.

$\$ 64.9$ m.eq. of magnesium given during the previous night.

\& Forty-eight hours later. 
end of the infusion associated with this 13.3 value, this second patient became very drowsy and responded only with difficulty; sensitivity to painful stimuli was also much reduced. These symptoms disappeared not long after the end of the infusion. Levels of 4 to $10 \mathrm{~m}$.eq. per liter were not accompanied by anesthesia, coma, motor paralyses, absence of deep reflexes, or any subjective sensation other than the feeling of warmth during the injection. This confirms the observations of Peck and Meltzer (4), who found that amounts sufficient to raise the concentration to about 15 m.eq. per liter (estimated) were necessary to produce surgical anesthesia in man. It is also consistent with the observations of Neuwirth and Wallace (17) and of Hoff, Smith and Winkler (18) that levels in excess of 10 m.eq. per liter are necessary to produce neuromuscular block and evidence of narcosis in dogs.

The rate of decline of the concentration of magnesium in the serum of subjects with high blood NPN values is very slow. Thus in the first five cases of Table II the magnesium concentration had usually dropped only a milliequivalent or so by the next morning. This rate of disappearance means that an elevated concentration must persist for several days. On the other hand, the rate of disappearance from the serum was very rapid in those patients whose renal function was more nearly normal (patients Number eight and Number nine), so that the concentration had virtually returned to normal by the next day. The urinary excretion is correspondingly low in the patients with markedly impaired renal function. Thus only 8 per cent of the injected magnesium was recovered from the urine in the twenty-four hours following the infusion in patient Number five. In Case eight, on the other hand, with a normal NPN, the entire amount injected on December 31 was recovered from the urine the next day. Stool excretion was not increased following magnesium injection (patient Number three), so it must be assumed that the main channel of excretion of injected magnesium is the urine, and that in advance nephritis with depressed clearances this excretion is ordinarily much impaired. The importance of renal excretion in the elimination of injected magnesium is consistent with the results of McCance and Widdowson with normal men (19) and of Smith, Winkler and Schwartz with dogs (14).

In the last column of Table II are tabulated the apparent volumes of distribution of the injected magnesium in cases with renal insufficiency. These values were calculated by the formula (14):

Volume of distribution (per cent of body weight)

$$
=\frac{\text { Amount of } \mathrm{Mg} \text { injected }}{\text { Increase in concentration of } \mathrm{Mg} \text { in serum }} \times
$$

$100 \times 0.93$

$\overline{\text { Body weight }}$

This calculation ignores the urinary excretion during the period of injection, an omission which is only justified by the low rate of excretion of magnesium in patients with renal insufficiency. It cannot be applied to the cases with normal or slightly reduced renal function. The factor 0.93 is assumed to be the fraction of water in serum. The results indicate that the immediate apparent volume of distribution varies between 19 and 40 per cent of the body weight and tends to be higher in edematous than in non-edematous subjects. These figures are consistent with those obtained in normal animals and indicate that the greater part of the injected magnesium is, at least at first, confined to the extracellular fluid (14).

\section{DISCUSSION}

Intravenous magnesium in the amounts given is apparently of some value in preventing and controlling the development of convulsions in chronic nephritis. These benefits, such as they are, occur with amounts of magnesium so small that in animals comparable amounts produce no demonstrable depression of the nervous system $(17,18)$. They do, however, produce pronounced vasodilatation (20), and in man the same vasodilatation is regularly observed. It seems at first sight reasonable, therefore, to ascribe the therapeutic effectiveness of the ion more to this vasodilatation than to nervous system depression. This interpretation is, however, not consistent with the observation that in many of the cases of chronic nephritis no fall in blood pressure occurred. It is precisely in the chronic group that beneficial effects were also so irregular, in contrast to the much more consistent fall in blood pressure with clinical improve- 
ment in the subjects with acute nephritis and eclampsia. That some moderate peripheral or central depression of the nervous system occurred as well cannot, of course, be excluded. With repeated injections of magnesium (Table II $(5,8)$ ), the concentrations of magnesium rose above 10 m.eq. per liter, and with such concentrations depressions of the nervous system are demonstrable in dogs $(17,18)$. Slow single injections of 500 cc. of 2 per cent $\mathrm{MgSO}_{4}$ did not raise the serum magnesium to this extent.

The slow excretion of magnesium in the urine of nephritic patients caused a persistent elevation of magnesium in the serum, lasting some hours or days. This makes repeated doses more effective and at the same time more dangerous. Since $1000 \mathrm{cc}$. of 2 per cent $\mathrm{MgSO}_{4}$ will raise the magnesium concentration to the 10 to $15 \mathrm{~m}$.eq. per liter level, and since in animals respiratory failure occurs at 15 m.eq. per liter, not more than two injections of $500 \mathrm{cc}$. each should be given within a period of two or three days. The situation with patients with eclampsia is not comparable, since renal function is usually more nearly normal and rapid elimination of the magnesium from the blood stream is to be expected.

The concentrations of magnesium attained were insufficient to cause respiratory arrest in any instance, but in several patients mild depression of respiration was observed. In all such cases tendon reflexes had already disappeared. The results obtained with animal experiments (18) were thus confirmed, in that knee jerks disappear at a concentration of magnesium below that at which respiration fails. Practical advantage may be taken of this fact in regulating the amount and rate of injection of magnesium in man. So long as the knee jerks are active, there is no need to be concerned about respiratory failure, while their disappearance is a warning sign.

The return of the blood pressure to its previous level in the continued presence of an elevated concentration of magnesium in serum may only mean that the concentration, though still greater than normal, has fallen below the critical level necessary to overcome vasoconstrictor impulses. During intravenous injection the rate of diffusion of magnesium out of the blood stream into the tissues may well be somewhat less than the rate of injection, so that the concentration rises sharply in the serum. So long as this is in progress a concentration greater than that in tissues and sufficient to lower the blood pressure may be temporarily maintained in the circulating serum. After the infusion is concluded, magnesium in serum will gradually decline until equilibrium with tissue fluids is reached, even if excretion is negligible. The greater persistence of hypotension in subjects with renal impairment than in those without may in part be due to the more rapid fall of magnesium of serum in the latter, due to urinary excretion as well as diffusion. It is also possible that powerful vasoconstrictor forces may be called into play in order to antagonize the action of magnesium. The nature of these hypothetical stimuli is as obscure as the locus of action of magnesium itself. Even after a marked hypotension has been induced by magnesium, any muscular activity of the patient raises the blood pressure sharply. From the ease and rapidity with which the fall of blood pressure may be reversed, it may reasonably be concluded that there is no capillary paralysis such as is seen in "shock." It seems reasonable to believe that the main site of its action is the arteriole. In this event it must be assumed that in the unresponsive subjects the cutaneous vessels dilate but that the splanchnic or somatic vessels contract, thus maintaining the blood pressure.

The effects on the cardiovascular system are not entirely comparable to those obtained experimentally in normal dogs $(20,21)$. Both cutaneous vasodilatation and fall in blood pressure are present in the dog. These follow the injection of amounts too small to exert any demonstrable effect on the nervous system. The fall in pressure, however, is apt to be gradual in the dog and the sudden collapse seen in normal man was not observed. Indeed, the normal dogs behaved more like the hypertensive patients. The action in dogs is usually transient, but repeated doses are effective each time and there is a tendency for the blood pressure to remain at a somewhat reduced level as long as an elevation of magnesium in the serum persists. This vasodilator effect occurs with as little as 3 to 5 m.eq. of magnesium per liter of serum, whereas motor paralysis and respiratory arrest do not occur until a level of 10 to 15 m.eq. is attained. Significant electrocardiographic changes also occur during magnesium injection in the dog, consisting chiefly of progressive pro- 
longation of the $\mathrm{PR}$ interval and, finally, bradycardia and cardiac arrest (21). These changes are, however, barely manifest at levels below 15 m.eq. per liter and can often be demonstrated only with the aid of artificial respiration. The slight changes observed in man are entirely comparable with those produced in the dog by similar concentrations of magnesium in the serum.

\section{CONCLUSIONS}

1. The slow intravenous injection of $500 \mathrm{cc}$. of 2 per cent magnesium sulfate $\left(\mathrm{MgSO}_{4} \times 7 \mathrm{H}_{2} \mathrm{O}\right)$ is a safe procedure which is of some value in preventing and controlling the convulsive seizures of chronic nephritis in adults. The benefits are, however, neither certain nor dramatic.

2. If convulsions are not controlled by a single injection, they will almost always be checked by a second injection. After two injections magnesium may attain such a high concentration in serum that its depressant effects on the nervous system may become manifest.

3. After injection the concentration of magnesium may remain elevated for several days in patients with chronic nephritis because of the retarded excretion of magnesium in the urine. More than $1000 \mathrm{cc}$. of 2 per cent magnesium sulfate should therefore not be given within a forty-eighthour period in the presence of severe renal insufficiency, lest a concentration sufficient to produce respiratory paralysis be attained.

4. Magnesium in these amounts causes cutaneous vasodilatation in all subjects. Blood pressure regularly falls in subjects with acute nephritis or eclampsia but is frequently unaffected in those with chronic cardiovascular disease.

\section{BIBLIOGRAPHY}

1. Meltzer, S. J., Inhibitory properties of magnesium sulfate and their therapeutic application in tetanus. J. A. M. A., 1916, 66, 931.

2. Blake, J. A., The use of magnesium sulfate in the production of anesthesia and in the treatment of tetanus. Surg. Gynec., and Obst., 1906, 2, 541.

3. Meakins, J. C., The Practice of Medicine. Second edition, C. V. Mosby Co., St. Louis, 1938, p. 1239.

4. Peck, C. H., and Meltzer, S. J., Anesthesia in human beings by intravenous injection of magnesium sulfate. J. A. M. A., 1916, 67, 1131.

5. Beckman, H., The alleged synergism of magnesium sulphate and morphine. J. A. M. A., 1925, 85, 332.
6. Blackfan, K. D., and Hamilton, B., Uremia in acute glomerular nephritis. Boston M. and S. J., 1925, 193, 617.

7. Blackfan, K. D., and McKhann, C. F., Acute glomerular nephritis in children. Treatment of cerebral manifestations. J. A. M. A., 1931, 97, 1052.

8. Rubin, M. I., and Rapoport, M., The mode of action of magnesium sulfate in reducing the hypertension of acute glomerulonephritis. Am. J. M. Sc., 1941, 201, 734.

9. Lazard, E. M., A preliminary report on the intravenous use of magnesium sulphate in puerperal eclampsia. Am. J. Obst. and Gynec., 1925, 9, 178.

10. Alton, B. H., and Lincoln, G. C., The control of eclampsia convulsions by intraspinal injections of magnesium sulphate. Am. J. Obst. and Gynec., 1925, 9, 167.

11. Lazard, E. M., Irwin, J. C., and Vruwink, J., The intravenous magnesium sulphate treatment of eclampsia. A collective report of 142 cases. Am. J. Obst. and Gynec., 1926, 12, 104.

12. Stroganoff, W., and Davidovitch, O., Two hundred cases of eclampsia treated with magnesium sulphate $\left(\mathrm{MgSO}_{4}\right)$ : a preliminary report. J. Obst. and Gynaec. Brit. Emp., 1937, 44, 289.

13. Lazard, E. M., An analysis of 575 cases of eclampsia and preeclamptic toxemia treated by intravenous injection of magnesium sulphate. Am. J. Obst. and Gynec., 1933, 26, 647.

14. Smith, P. K., Winkler, A. W., and Schwartz, B. M., The distribution of magnesium following parenteral administration of magnesium sulfate. J. Biol. Chem., 1939, 129, 51.

15. Foster, N. B., Uraemia. Harvey Lectures, 1920-1921, p. 52.

16. Merritt, H. H., and Fremont-Smith, F., The Cerebrospinal Fluid. W. B. Saunders, Phila., 1937.

17. Neuwirth, I., and Wallace, G. B., On the use of magnesium as an aid in anesthesia. J. Pharmacol. and Exper. Therap., 1929, 35, 171.

18. Hoff, H. E., Smith, P. K., and Winkler, A. W., Effects of magnesium on the nervous system in relation to its concentration in serum. Am. J. Physiol., 1940, 130, 292.

19. McCance, R. A., and Widdowson, E. M., The fate of calcium and magnesium after intravenous administration to normal persons. Biochem. J., 1939, 33, 523.

20. Hoff, H. E., Smith, P. K., and Winkler, A. W., The relation of blood pressure and concentration in serum of potassium, calcium and magnesium. Am. J. Physiol., 1939, 127, 722.

21. Smith, P. K., Winkler, A. W., and Hoff, H. E., Electrocardiographic changes and concentration of magnesium in serum following intravenous injection of magnesium salts. Am. J. Physiol., 1939, 126, 720 . 